\title{
Gradhiva
}

GRADHIV

Revue d'anthropologie et d'histoire des arts

18 | 2013

Le monde selon l'Unesco

\section{Le secret exposé. Révélation et reconnaissance d'un patrimoine immatériel au Sénégal}

The secret exposed: revelation and recognition of intangible heritage in Senegal

\section{Ferdinand De Jong}

Traducteur : Traduction de l'anglais par Camille Joseph

\section{OpenEdition}

Journals

Édition électronique

URL : http://journals.openedition.org/gradhiva/2722

DOI : $10.4000 /$ gradhiva. 2722

ISSN : 1760-849X

Éditeur

Musée du quai Branly Jacques Chirac

Édition imprimée

Date de publication : 1 décembre 2013

Pagination : 98-123

ISBN : 978-2-35744-072-2

ISSN : 0764-8928

Référence électronique

Ferdinand De Jong, «Le secret exposé. Révélation et reconnaissance d'un patrimoine immatériel au Sénégal », Gradhiva [En ligne], 18 | 2013, mis en ligne le 01 décembre 2016, consulté le 01 mai 2019. URL : http://journals.openedition.org/gradhiva/2722 ; DOI : 10.4000/gradhiva.2722 



\section{Le secret exposé}

Révélation et reconnaissance d'un patrimoine immatériel au Sénégal

par Ferdinand de Jong

En 2005, la cérémonie du kankurang

et les rites d'initiation mandingues sont proclamés chefs-d'œuvre du patrimoine oral et immatériel par l'Unesco. II s'agit ici d'analyser la façon dont la patrimonialisation de la cérémonie a progressivement conduit à sa marchandisation. Cet article, qui rejette l'idée d'une culture "originale", s'inscrit dans les réflexions actuelles sur la marchandisation du patrimoine selon lesquelles culture et marchandise ne s'opposent pas mais sont au contraire mutuellement constitutives l'une de l'autre. Selon ce point de vue, on considère que l'objectification du patrimoine, loin de freiner le changement culturel, y participe pleinement. En se focalisant sur la façon dont la cérémonie est objectifiée par le regard des spectateurs, l'article montre que les participants à la cérémonie eux-mêmes ont adopté un autre régime visuel afin d'obtenir la reconnaissance de leur art. Cette étude de cas espère remettre en question des lectures trop pessimistes de la marchandisation qui présupposent que toute transformation culturelle ne peut aboutir qu'à la perte. 


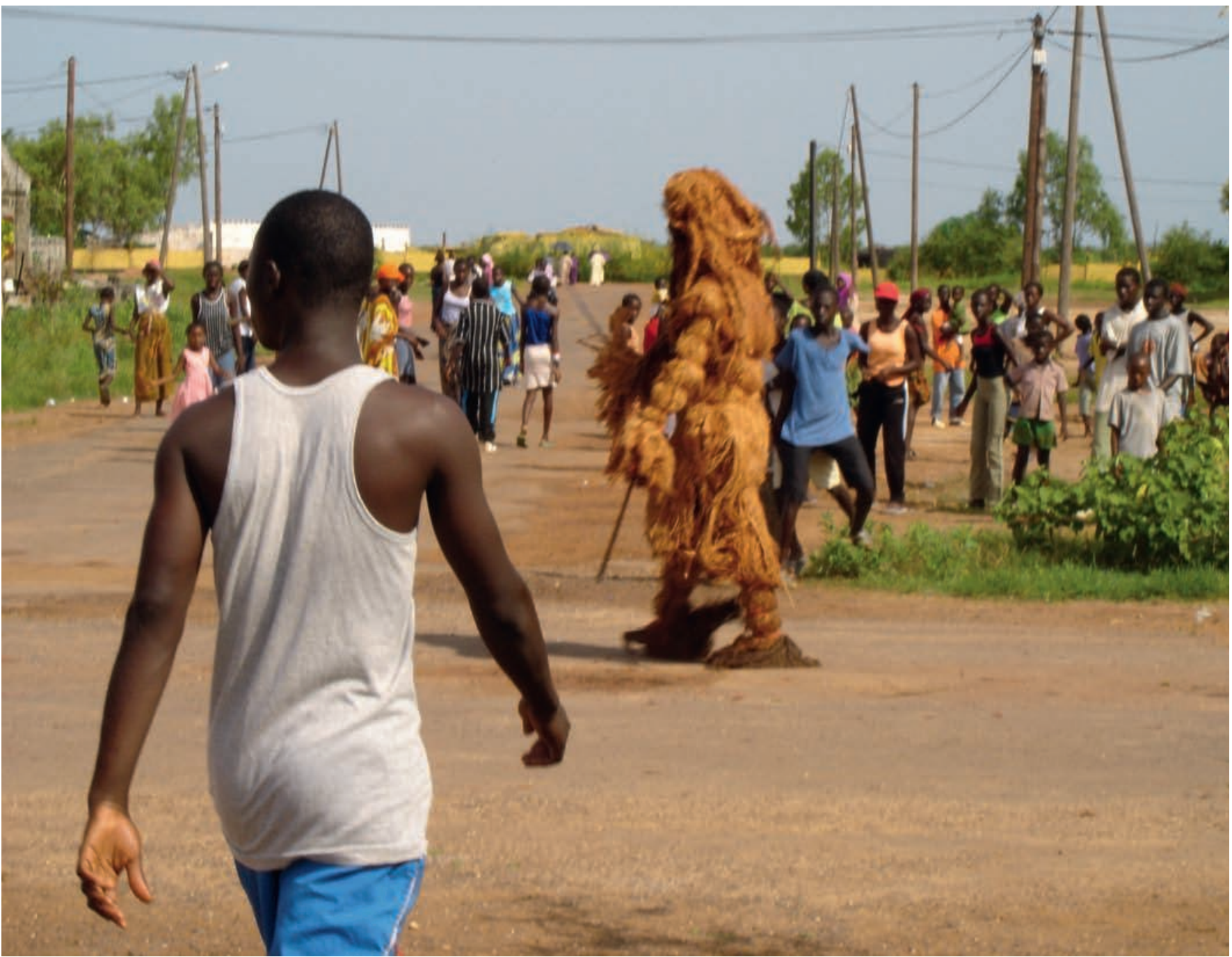

fig. 1

Cérémonie de kankurang, 2004. (C) Ferdinand de Jong.
Parmi les quarante-trois nouveaux chefs-d'œuvre du patrimoine oral et immatériel de l'humanité proclamés comme tels par l'Unesco en 2005 figurent le kankurang et le rite d'initiation en société mandingue, présentés par le Sénégal et la Gambie (UnescoPress 2005). Cette cérémonie de masques, pratiquée dans les deux pays au cours des rites de circoncision et d'initiation, bénéficie désormais de la reconnaissance et du soutien institutionnel de I'Unesco en faveur de sa sauvegarde. Cette nouvelle m'a beaucoup surpris. En effet, la cérémonie, que j'avais étudiée pendant des années et qui était généralement perçue comme une tradition «dégénérée», était tout à coup réhabilitée sur le plan international en devenant patrimoine culturel immatériel. Ce rite se voyait ainsi offrir la perspective d'une seconde vie en tant que patrimoine culturel.

Le processus de patrimonialisation transforme des traditions vivantes «originales» en formes culturelles réflexives et, par suite, des chercheurs ont avancé l'idée selon laquelle le patrimoine n'était plus alors un habitus mais revêtait des aspects métaculturels (Kirshenblatt-Gimblett 2006). Ce qui était autrefois authentique devient une marchandise comparable à d'autres, 
tous ces biens patrimoniaux figurant sur des listes de lieux à visiter et d'expériences à faire. Nombreux sont ceux qui mettent ainsi en garde contre la transformation de l'original sur le marché du patrimoine mondial, faisant écho aux réflexions de Walter Benjamin sur la perte de l'aura de l'œuvre d'art à l'ère de sa reproductibilité technique (Benjamin 2003). Pour Benjamin, la reproduction mécanisée d'une œuvre d'art a pour effet de lui faire perdre son pouvoir unique de fascination. Cette vision nostalgique de l'œuvre a profondément influencé notre conception de l'art et continue d'avoir un impact sur notre façon d'évaluer le patrimoine en tant que dépositaire de l'original. Mais une lecture aussi univoque du changement culturel est discutable: l'idée qu'il existerait un original ne fait en réalité que sous-tendre une idéologie de l'authenticité au sein d'une économie politique où les simulacres prévalent et où l'«authentique» n'est qu'une chimère de plus (Baudrillard 1981). Est-il véritablement possible de séparer le patrimoine immatériel d'une économie du signe et de décider de l'authenticité d'un quelconque original? Contre l'idée d'une culture authentique, cet article s'inscrit dans les réflexions actuelles autour de la marchandisation du patrimoine qui ne conçoivent pas culture et marchandise comme deux entités opposées, mais interdépendantes (voir Comaroff et Comaroff 2009; Ethnologia Europaea 2009). Dans cette perspective, l'objectification du patrimoine ne va pas à l'encontre du changement culturel: elle y participe au contraire pleinement. Avec l'étude de terrain présentée ici, j'espère remettre en question des lectures trop pessimistes de l'objectification selon lesquelles tout changement culturel ne peut qu'entraîner la perte, cette idée étant à l'origine de l'ethnographie de sauvetage pratiquée au XIX siècle (Clifford 1996). Au contraire, je montrerai qu'il existe toujours différents registres des cérémonies en question. Bien qu'ils puissent être parfois contradictoires, cela ne tient pas à l'inscription sur la liste de l'Unesco: cet article vise en effet à montrer que de telles contradictions existent depuis la colonisation française, période pendant laquelle ces cérémonies culturelles furent «traduites » en spectacles.

À travers le cas étudié ici, qu'il faut replacer dans une réflexion sur l'impact de l'inscription et de la «canonisation » par l'Unesco sur le patrimoine immatériel (Smith et Akagawa 2009), je propose une lecture de la patrimonialisation où l'objet patrimoine est resitué dans des registres différents qui coexistent et coïncident. Nous avancerons ainsi l'idée selon laquelle la proclamation du kankurang comme patrimoine immatériel doit être replacée dans le contexte d'une politique culturelle visant à transformer les cérémonies rituelles en spectacles et, ainsi, à faire reconnaître leur existence. Si le secret entourant le rite est mis à mal par cette spectacularisation, la cérémonie accède néanmoins par ce biais à la reconnaissance. En outre, elle prend en compte celle-ci, l'intègre au déroulement du rite et, par là même, parvient ainsi à se réinventer. Grâce aux technologies du patrimoine (De Jong et Rowlands 2007), les acteurs de la cérémonie réussissent à mettre en place leurs propres stratégies de réalisation personnelle.

\section{Secret et violence}

Dans les années 1990, pendant mon travail de terrain sur la cérémonie du kankurang en Casamance (au sud du Sénégal), mes informateurs ne manquaient jamais de m'exposer leur conception de la cérémonie en utilisant le présent ethnographique. Puisque leurs discours nostalgiques 


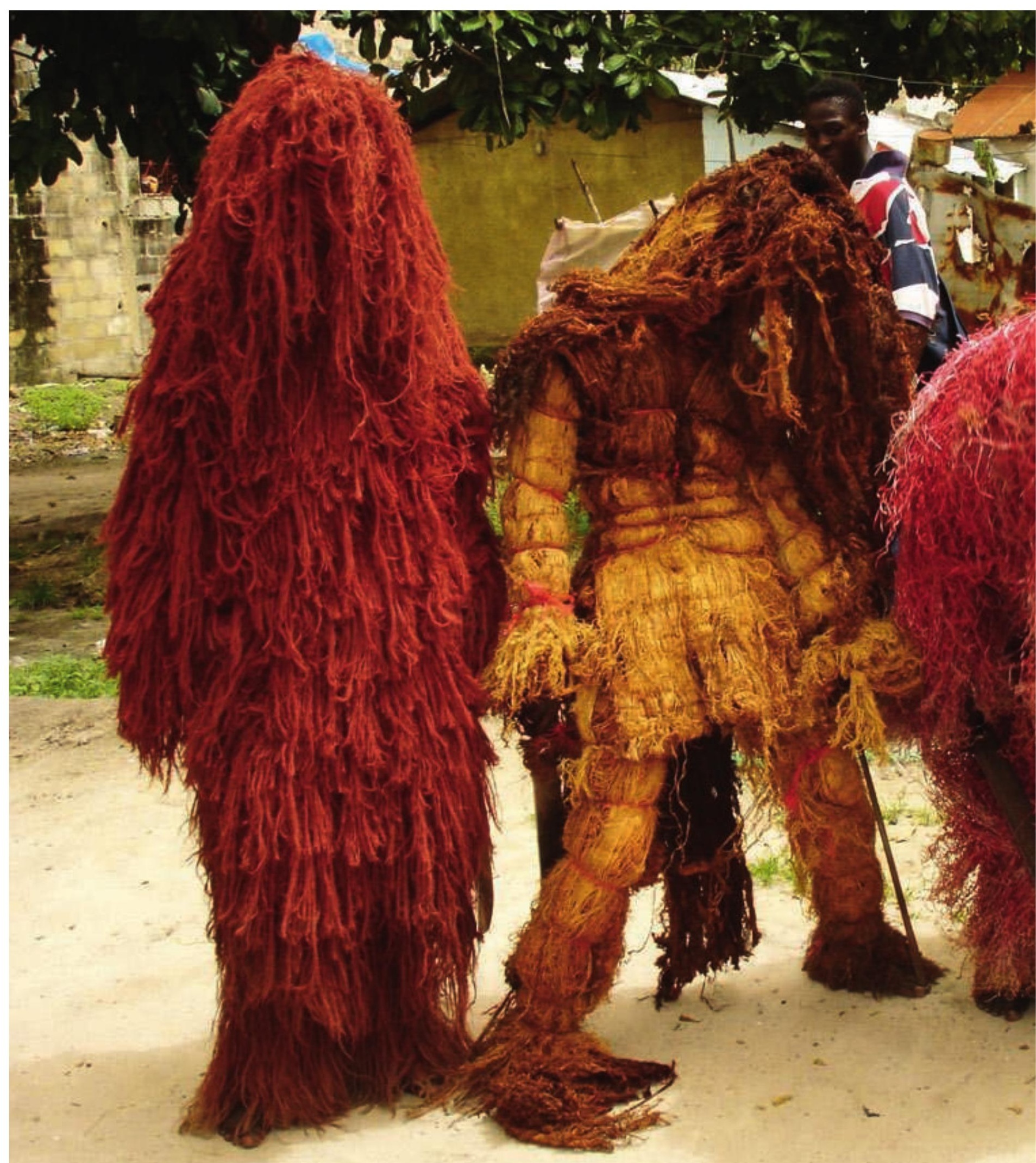




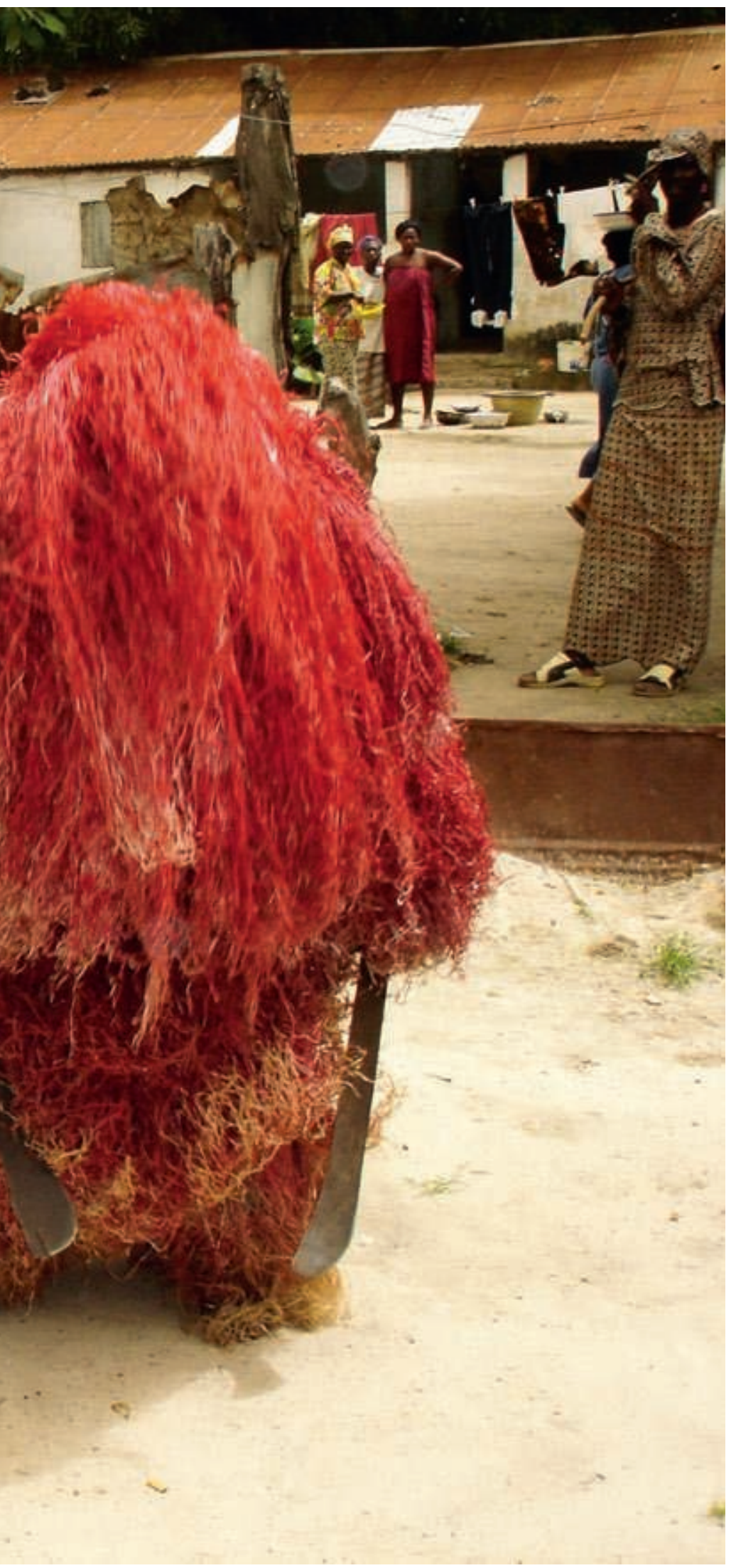

fig. 2

Trois Kankurangs posant pour le photographe à Ziguinchor, 2004. On y voit les différents matériaux qui composent les costumes: l'écorce de Fara sur le personnage central; sur les deux autres, les costumes dits Sisal, sont faits à partir de matériaux industriels récupérés tels

que des sacs de riz.

(c) Ferdinand de Jong. 
mêlaient passé et présent, j'éprouvais la plus grande difficulté à distinguer la fiction de la réalité. Il était bien souvent impossible de dire s'ils me peignaient une image fidèle de la façon dont les choses se passaient autrefois ou si ce n'était là qu'un passé idéalisé particulièrement bien adapté à leur discours sur un présent «dégénéré». En effet, un tel récit correspond bien à l'image de l'Afrique comme terre de civilisations disparues, l'un des mythes les plus tenaces depuis le début de la colonisation. Mais je vais reprendre ici le cadre de pensée de mes informateurs: la description du kankurang qui suit est ainsi rédigée au présent ethnographique, avec toute la distance réflexive que ce temps requiert.

La cérémonie des masques du kankurang est l'une des traditions culturelles des Mandingues, qui vivent en Guinée-Conakry, en Guinée-Bissau, au Sénégal et en Gambie. Le masque est composé de morceaux d'écorce qui couvrent tout le corps de telle manière qu'il est impossible d'identifier l'individu masqué. Le kankurang tient dans chaque main un coutelas, ce qui ajoute un aspect terrifiant à son apparition mystérieuse (fig. 2). II annonce sa sortie par un cri puissant au son duquel les spectateurs partent se cacher en courant. Il est généralement accompagné par une dizaine de jeunes hommes qui portent des bâtons et menacent de frapper les spectateurs, souvent nombreux à assister à la cérémonie. Les individus accompagnant le kankurang sont redoutés car leurs actes sont attribués au masque, qui agit lui-même en toute impunité. Ils peuvent ainsi adopter une attitude licencieuse, et la cérémonie donne souvent lieu à des scènes violentes. Historiquement, le kankurang servait à faire respecter les règles fixées par la société secrète des initiés et, à ce titre, avait le droit d'user de la violence.

Le fait que le masque est en réalité un homme déguisé est un secret, révélé à l'initié au cours de son initiation. Tous les initiés sont moralement obligés de garder le silence sur la nature du masque. Des conflits éclatent parfois entre les individus appartenant à la communauté défendant le secret de l'initiation et ceux qui cherchent à le connaître. Les histoires populaires, qui prennent souvent la cérémonie pour sujet, décrivent de manière récurrente de telles confrontations. Mes informateurs m'ont cité de multiples exemples d'altercations violentes entre le masque et des adversaires qui lui avaient vraisemblablement manqué de respect (fig. 3). Bien que, dans certains cas, ces violations du secret soient finalement réparées par le versement d'une amende, elles sont parfois punies de mort (De Jong 2007). Mais quelle que soit l'issue du conflit, les récits populaires donnent immanquablement raison au kankurang.

Ce rite se déroule habituellement au cours de l'initiation des garçons. Dans les villages mandingues, ces initiations, auxquelles participe l'ensemble des habitants, ont lieu tous les cinq ans; dans la ville de Ziguinchor (en Casamance), où j'ai effectué la plus grande partie de mes recherches, elles ont lieu une fois par an. Organisées par les familles, elles ont pour but de purifier les garçons grâce à la circoncision. Lors de la cérémonie, le kankurang est censé protéger les circoncis des sorcières et des actes malfaisants qu'elles dirigeraient contre les garçons. II doit également empêcher les intrus de pénétrer dans le camp d'initiation, qu'il protège par des moyens magiques. Une des traditions orales sur l'origine de l'initiation masculine relate comment, 


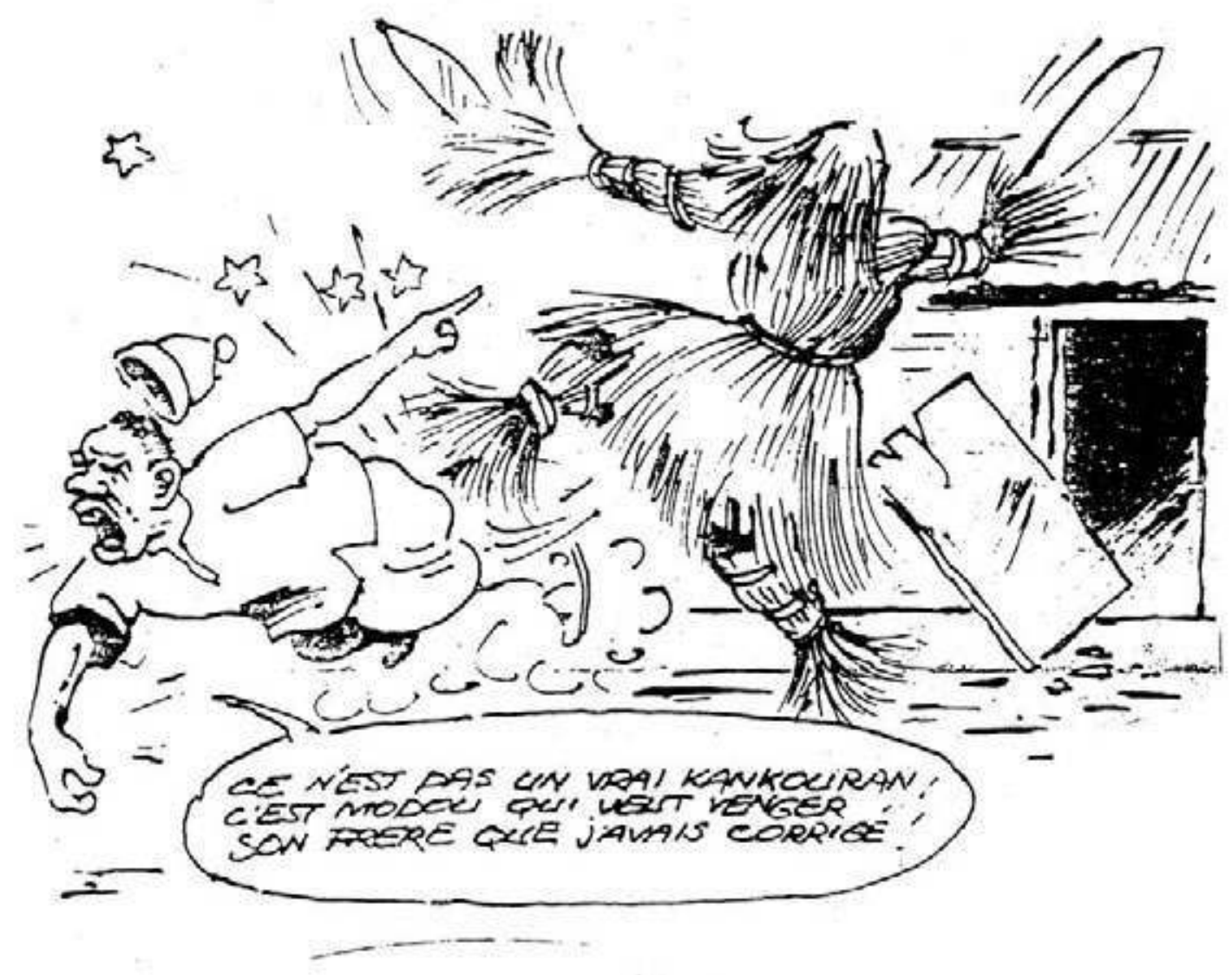

jadis, une femme très curieuse voulut savoir ce qui se passait dans le camp. Elle se transforma en oiseau et pénétra subrepticement dans la forêt sacrée où les initiés étaient gardés à l'écart par le kankurang. C'est alors qu'elle fut découverte, rouée de coups par le kankurang et aveuglée pour la punir de sa curiosité et de sa transgression. La tradition orale rapporte que «voir» des choses interdites aux non-initiés entraîne la perte de la vue. La cérémonie est ainsi évoquée sur le mode du secret, les initiés seuls étant légitimement autorisés à connaître le kankurang.

\section{À l'ère de la reproductibilité technique}

La nuit, quand le masque parcourt la ville en tous sens, il émet un cri auquel répondent ses gardiens: Thior Mama, issabari! (Notre Père, pardonnenous!), Asé! Afa! (Tue! Coupe!) Lors de la cérémonie, les spectateurs tiennent lieu de sorcières potentielles qu'il faut persécuter. II ne leur reste alors plus qu'à fuir et se cacher. L'interdiction de voir le kankurang fait partie du scénario et est mise en scène. Les femmes et les non-initiés ne doivent pas regarder le masque, manifestant ainsi leur soumission. Aujourd'hui encore, ce dernier poursuit les spectateurs et menace de frapper quiconque se trouve à sa portée, en particulier les femmes. Par conséquent, personne ne peut assister à la cérémonie sans craindre d'être attaqué par le masque ou ses gardiens. Le rite fait peur, ce qui lui confère l'aura typique des cérémonies de ce genre: en rendant le kankurang inapprochable, il permet de

fig. 3

Dessin de Samba Fall paru dans le quotidien sénégalais Le Soleil, s.d., DR. 
fig. 4

Les photographies de Kankurangs sont réputées être toujours ratées, 2004 (C) Ferdinand de Jong. maintenir la distance essentielle qui sépare le masque des spectateurs (voir Benjamin 2003: 22-23; "le caractère inapprochable est l'une des principales caractéristiques de l'image servant au culte»).

L'interdiction de regarder la cérémonie s'applique également aujourd'hui à toutes les techniques de reproduction mécanique, telle la photographie. Au début de mes recherches, il me fallut attendre plusieurs semaines avant d'avoir la chance d'assister à une cérémonie: je vis alors le kankurang danser sur le dos de ses gardiens allongés dans la rue en signe de soumission (fig. 6). Mon assistant me suggéra de prendre une photographie. Mais l'un des gardiens surgit tout à coup devant moi et m'arracha l'appareil des mains: troublé par la violence d'un tel geste, je restai perplexe. Après de patientes négociations par l'intermédiaire de mon assistant, on m'autorisa à racheter mon appareil. Cette scène était bien entendu une des nombreuses provocations des gardiens du kankurang, mais ces derniers justifièrent leur geste en disant que la photographie aurait pu être transformée en carte postale. C'était bien cela, disaient-ils, qu'ils voulaient empêcher. Je les rassurai sur mes intentions et on me laissa conserver la pellicule. Mais le cliché était raté (fig. 4).

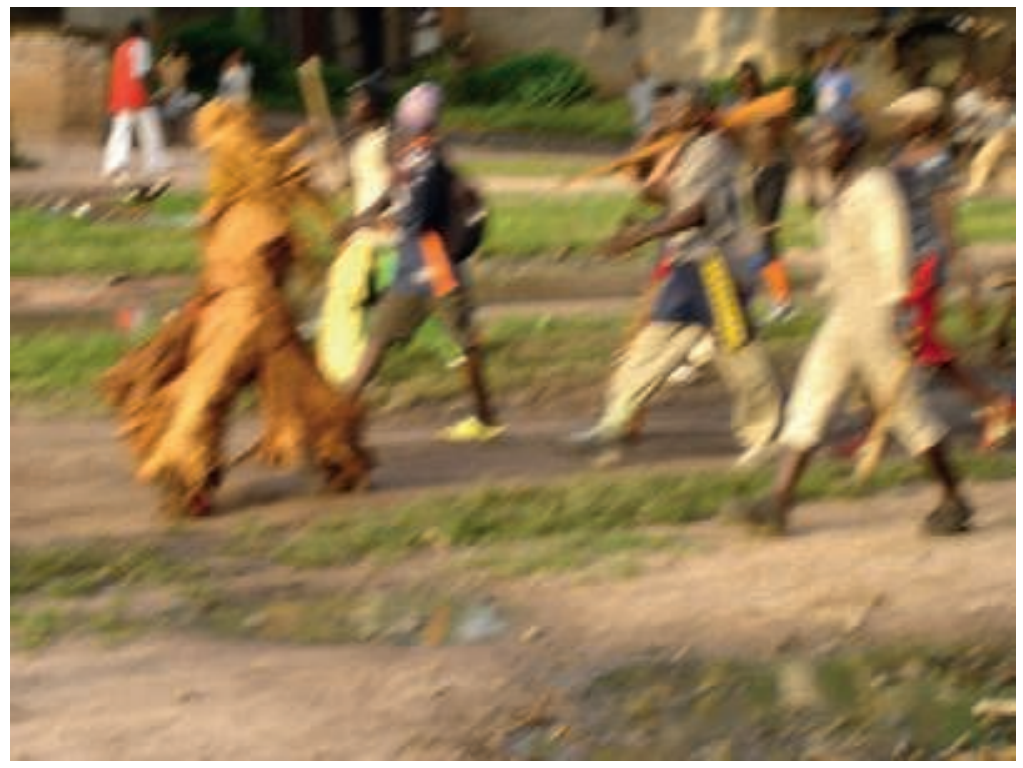

Le geste des gardiens et la façon dont ils le justifièrent laissent entrevoir la relation qui s'est tissée au cours de l'histoire entre la photographie, l'ethnographie et le désenchantement lié à la reproductibilité technique (voir Benjamin 2003). À de multiples reprises, on m'a dit qu'il ne fallait pas photographier le masque car cela lui ferait perdre son pouvoir. Cette idée relève d'un discours plus général interdisant toute représentation du secret/ sacré; or ce même discours attribue précisément au secret/sacré le pouvoir de subvertir les images de lui-même reproduites mécaniquement (voir Spyer 2001: 315). On entend ainsi souvent dire que les photographies du kankurang sont toujours ratées. Cela ne peut que jouer en faveur d'une cérémonie réussie: la terreur que le kankurang fait régner ne doit pas être prise à la légère, et les spectateurs doivent manifester leur peur en fuyant le masque. L'interdiction de «voir» la cérémonie a connu un prolongement contemporain puisque aujourd'hui touristes et anthropologues n'ont pas le 


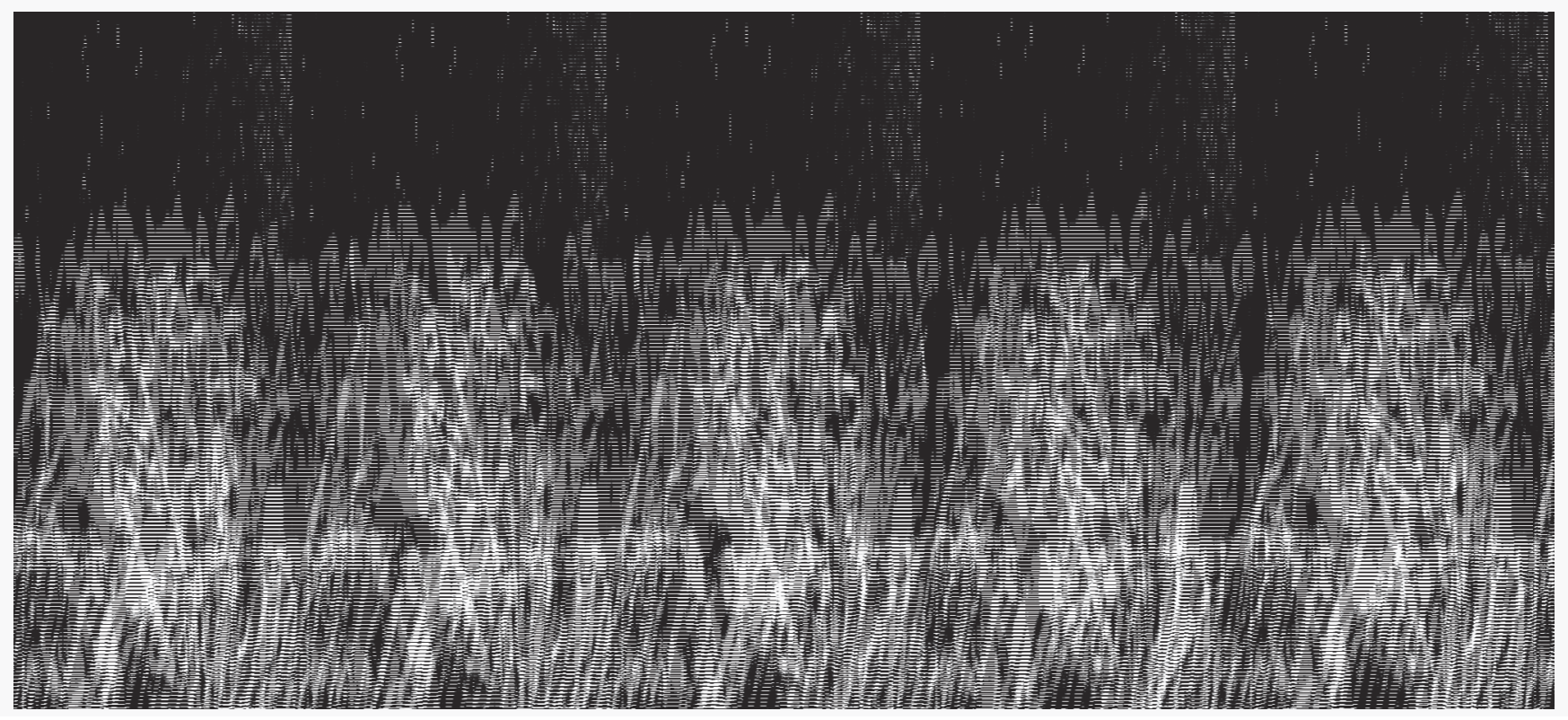

droit de prendre des photographies (fig. 5). Les spectateurs doivent feindre d'avoir peur afin de nourrir la croyance générale dans le pouvoir surnaturel du masque. Il est intéressant de noter que cette interdiction est elle-même mise en scène au cours de la cérémonie. Si elle peut se justifier par le fait que la photographie est censée affaiblir le sacré/secret, c'est en réalité la représentation de l'interdiction au cours de la cérémonie qui alimente l'aura du kankurang. On pourrait ainsi dire que la version contemporaine de la cérémonie est conditionnée par la possibilité d'être reproduite mécaniquement; son aura est le produit d'une représentation qui, de manière délibérée, rend impossible d'en tirer des images reproduites mécaniquement. L'aura du rituel, qui s'est adapté à la possibilité d'être reproduit mécaniquement, est aujourd'hui complètement mêlée à celle de sa reproduction.

\section{Le secret perdu}

Dans la ville de Ziguinchor, le rite du kankurang existe depuis le début du xx ${ }^{e}$ siècle. Cependant, dans les années 1980, un grand nombre d'habitants déplorèrent la «banalisation » ou encore la « dégénération » de la cérémonie. Ils prétendaient que, par le passé, le kankurang était capable de réaliser des miracles et de combattre sorcières et autres mauvais esprits. II était dangereux, et on pensait que ceux que le masque avait frappés succombaient plus tard aux effets de sa magie. Selon les tenants de ce discours nostalgique sur le pouvoir magique du masque, le public était autrefois plus respectueux du kankurang. Quand le masque errait la nuit de par les rues, on éteignait les feux de cuisson et les lumières tandis que les femmes s'enfermaient chez elles. On rapporte que ces dernières ne voyaient jamais le masque.

Cependant, dans les années 1980, plus personne à Ziguinchor ne respectait ces règles. De plus en plus de citadins faisaient circoncire leurs fils au cours d'une cérémonie initiatique mineure (kuyandingo) [De Jong 2007]. Les novices du kuyandingo ne se retiraient pas dans un camp d'initiation fig. 5

Dessin de Samba Fall paru dans le quotidien sénégalais Le Soleil montrant le Kankurang en train de pourchasser un photographe.

17-18 septembre 1988, DR. 


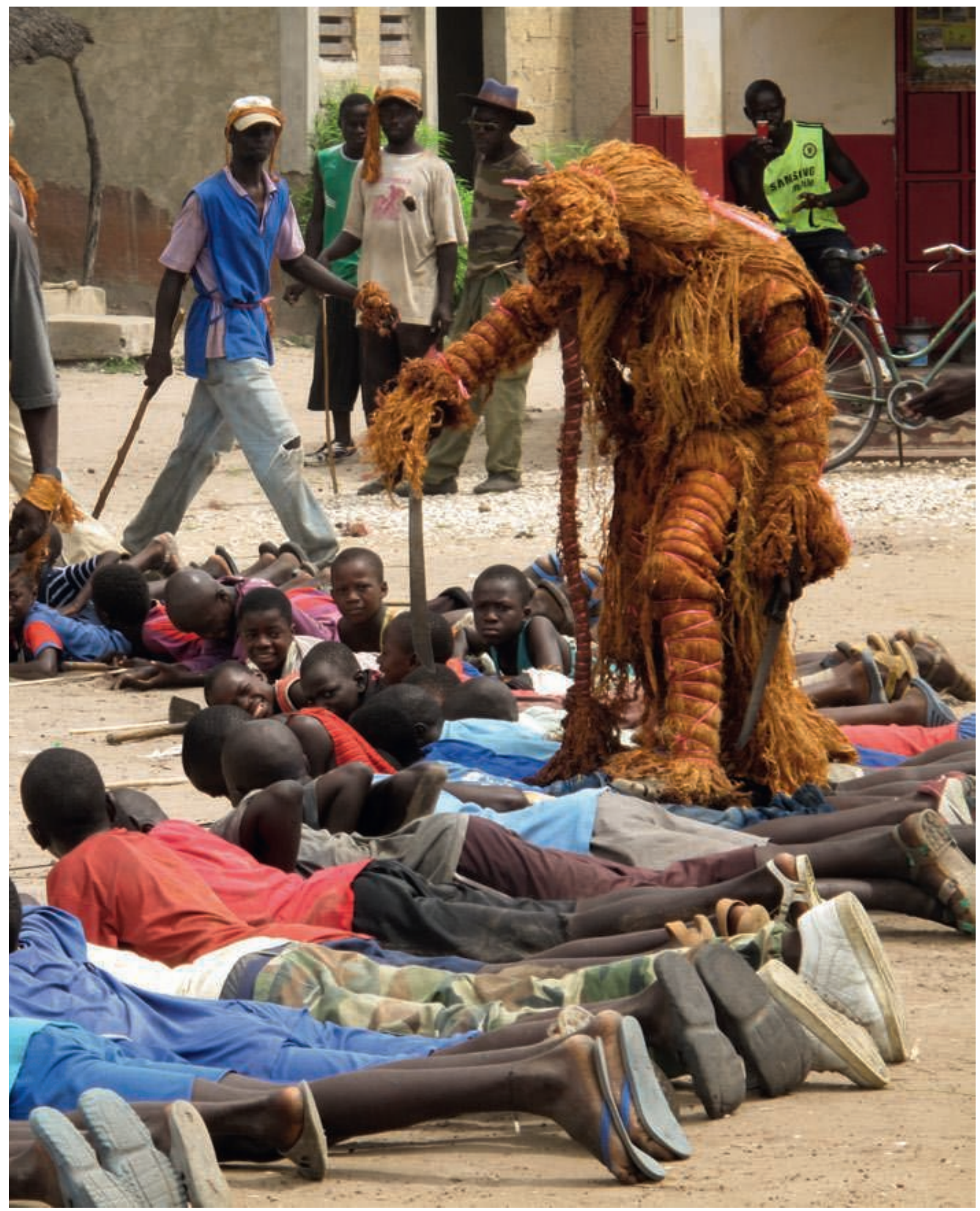


dans la brousse mais étaient isolés dans une pièce au sein même du domaine de leur père. Cette transformation des pratiques initiatiques eut un profond impact sur la dimension secrète de la cérémonie. Désormais, le kankurang revêtait son costume dans la pièce des novices, ne faisant plus aucun cas du secret autrefois si jalousement gardé. En outre, tandis que, dans la brousse, les initiations se déroulaient auparavant sous le regard attentif des aînés, le contrôle quotidien de l'initiation était désormais confié à des adolescents n'ayant aucune autorité sur les femmes. La cérémonie perdit en grande partie son caractère effrayant au profit de sa dimension ludique (fig. 6). Les kankurang se mirent à attirer des foules d'enfants ravis de prendre part à la scène. Ces derniers s'approchaient aussi près que possible du masque, et dès que celui-ci faisait un geste dans leur direction, ils s'enfuyaient en riant et allaient se cacher au coin de la rue la plus proche. Le masque ne faisait plus peur de la même manière. Ses jeunes porteurs allaient se vanter de leur performance auprès de leur petite amie. Au lieu de voir le masque chasser les sorcières la nuit, il devint de plus en plus courant de le voir courir après les filles pendant la journée.

À partir de ce moment, nombreux furent ceux qui estimèrent que la cérémonie avait perdu son pouvoir terrifiant et ne faisait plus peur aux femmes et aux novices. Selon eux, le masque n'inspirait plus le même respect car tout le monde connaissait désormais son secret. Ce discours nostalgique sur la perte du secret renvoyait le masque du côté de l'initiation, seuls les hommes initiés ayant le droit de voir le kankurang. Les transformations bien réelles qu'avait connues le rite signifiaient que le secret entourant l'initiation masculine était perdu. Dès lors, le kankurang devint une tradition dégénérée qu'il fallait sauver en réhabilitant son secret. Plusieurs dignitaires de Ziguinchor, qui jugeaient que les porteurs actuels du masque violaient le secret nécessaire à son efficacité, décidèrent de réguler les rites pratiqués dans leur ville. En 1988, plusieurs anciens - couramment désignés comme les «notables» locaux - entreprirent ainsi de contrôler la cérémonie. Ils se rendirent auprès du gouverneur et du chef de la police, et leur demandèrent d'intervenir pour freiner la banalisation du masque. Ils rendirent obligatoire l'obtention d'une autorisation officielle pour ses porteurs, qui ne devait être accordée qu'aux organisateurs de cérémonies se déroulant dans la brousse. Cette proposition fut acceptée par le gouverneur et le chef de la police, qui avaient encore en mémoire des conflits violents impliquant le kankurang (ibid.). Les cérémonies se firent rares à Ziguinchor pendant quelques années, mais elles réapparurent rapidement.

En 1994, Sana Diolo, porte-parole de la communauté mandingue de la ville, essaya une nouvelle fois de réguler les cérémonies. II animait deux émissions consacrées à la culture mandingue sur la radio locale, au cours desquelles était évoquée, le plus souvent par des anciens, la mise en péril des valeurs traditionnelles dans le monde moderne. Cette année-là, pendant la saison de la circoncision, il revint régulièrement au cours de ses émissions sur les vertus et les vices des rites kankurang. Étant donné que tout le monde s'accordait à penser que cette tradition dégénérée nécessitait une intervention, Diolo décida de reprendre le travail là où ses prédécesseurs l'avaient laissé et de mettre en place une réglementation. II fit adopter une résolution interdisant toute sortie de kankurang à Ziguinchor pendant cinq ans. Au bout 
1. Dans un article important, Michael Rowlands (2007) montre que le projet colonia de rénovation du patrimoine est en réalité une forme de nostalgie réparatrice. de cette période, les sorties furent à nouveau autorisées pendant les rites initiatiques se déroulant à l'extérieur de la ville, dans la brousse. Les habitants accueillirent très favorablement ces mesures, même si un certain mécontentement se fit entendre du côté des jeunes hommes qui prenaient un plaisir si manifeste à participer aux sorties du masque. Ainsi, pendant plusieurs années, aucune sortie du kankurang n'eut lieu dans la ville.

La réglementation de la cérémonie avait pour objectif de préserver l'aura du masque. Pour les dignitaires, celui-ci devait être un secret terrifiant, à la fois craint et admiré de tous. Il est intéressant de noter que seuls les kankurang se déroulant dans la brousse furent autorisés, cela afin d'exclure les femmes de l'espace rituel où le masque était vêtu. En redéfinissant ainsi le cadre approprié dans lequel devaient se dérouler les cérémonies, les dignitaires refusèrent également de donner aux jeunes hommes une quelconque autorité en la matière. Ce règlement ne fut pas du goût de ces derniers, qui ne se permirent cependant pas de contredire ouvertement leurs aînés. En renvoyant la cérémonie dans la brousse, les anciens replaçaient le masque dans l'espace cosmologique dont ils tiraient leur légitimité et leur autorité auprès des femmes et des jeunes. Ils tentèrent ainsi de restaurer une gérontocratie masculine, de toute évidence obsolète dans la ville moderne. De façon surprenante, ils se tournèrent vers l'administration pour faire imposer leurs décisions, admettant ainsi qu'ils ne contrôlaient plus les jeunes participant aux cérémonies. Étant donné le secret entourant le kankurang, cette démarche peut effectivement surprendre. Certains jeunes reprochèrent aux dignitaires d'avoir débattu des questions de règlement à la mairie plutôt que dans la brousse. Ils soulignaient ainsi l'ironie qui consistait à demander l'aide de l'administration pour gérer le secret de l'initiation. Cela montre que les anciens concevaient le kankurang comme une tradition soumise aux règles de droit. Le secret devait être restauré et contrôlé par l'État.

Les dignitaires adoptèrent des mesures destinées à restaurer l'aura du kankurang en limitant l'exposition du masque. En imaginant une réglementation visant à préserver la tradition, ils mirent en place une stratégie que Svetlana Boym (2001) a définie comme une «nostalgie réparatrice ${ }^{\mathbf{1}}$ ». Leur projet de restauration du secret exprimait une nostalgie pour un passé disparu qui devait certainement beaucoup à la nostalgie impérialiste de l'anthropologie française et à sa traduction dans la philosophie de la négritude du premier président du Sénégal, Léopold Sédar Senghor. Comme nous allons le voir, la proposition présentée à l'Unesco pour l'inscription de la cérémonie au patrimoine culturel immatériel définissait une politique patrimoniale faisant elle aussi écho à cette vision nostalgique. Cependant, la stratégie mise en place pour restaurer la tradition fut quant à elle très différente de celle des anciens de Ziguinchor.

\section{Les paradoxes de la patrimonialisation}

Le règlement adopté pour la cérémonie du kankurang peut être compris comme une manière de restaurer le rite. Or, à côté de cette stratégie visant à rétablir le secret, d'autres acteurs travaillèrent au contraire à rendre la cérémonie plus visible. Tandis que les dignitaires de Ziguinchor proposaient de limiter le nombre de performances, certains «ethno-preneurs» estimèrent qu'une meilleure reconnaissance de la cérémonie impliquait 
un changement de statut. En décembre 2004, un an avant la proclamation du kankurang comme chef-d'œuvre du patrimoine oral et immatériel de I'Unesco, se tint le Festival du diambadong à Sédhiou (en Casamance) (fig. 7). La manifestation, qui en était à sa deuxième édition, figurait déjà officiellement sur le calendrier culturel du Sénégal ${ }^{2}$. Un des organisateurs me confia que celle-ci avait pour objectif d'informer les jeunes de la ville sur le sens du kankurang car les cérémonies actuelles ne se conformaient pas aux normes traditionnelles du rituel. Au cours du festival, les jeunes auraient ainsi l'occasion d'assister à un «vrai » kankurang. L'organisateur de l'événement se posait visiblement les mêmes questions que celles qui avaient amené les notables de Ziguinchor à vouloir réglementer le rite dans leur ville. Mais je me rendis rapidement compte que les réponses qu'il y apportait étaient en réalité très différentes. Une des scènes les plus intéressantes fut celle de la cérémonie d'ouverture du festival. Après quelques mots de bienvenue prononcés par le maire de Sédhiou, l'un des invités attira l'attention sur les aspects éducatifs du diambadong et de la cérémonie initiatique. Pour illustrer son propos, il entonna des chants initiatiques que je croyais être secrets. Au son des percussions, le public se mit à chanter lui aussi, avant d'être rejoint par les dignitaires et les responsables politiques présents. L'ouverture du festival se termina dans une ambiance festive, chacun retrouvant avec plaisir l'esprit communautaire qu'il avait connu plus jeune pendant son initiation. Hommes et femmes étaient réunis dans un même espace, et personne ne trouva à redire sur le fait que ces chants étaient produits en public. Ces chants et danses initiatiques créèrent un vrai sentiment de convivialité. En fait, les habitants de la ville étaient déjà habitués à entendre ces chants en public car des groupes de musique populaire les avaient depuis longtemps intégrés dans leur répertoire ${ }^{3}$.

Le lendemain, un expert régional donna une conférence sur le kankurang à la mairie ${ }^{4}$. II mit en garde contre les effets destructeurs de la mondialisation sur la culture locale. II était non seulement nécessaire, selon lui, de "sauvegarder» le rituel, mais aussi de «commercialiser nos ressources culturelles». Son propos, non exempt de contradictions, révéla ainsi toutes les tensions qui s'accumulaient autour de la patrimonialisation du kankurang. Après une table ronde sur les paradoxes de ce phénomène, le public sortit pour assister à une cérémonie. Le long de la mairie, des chaises avaient été disposées pour les participants à la table ronde, les autres spectateurs restant debout. Un kankurang apparut et se mit à poursuivre ces derniers tandis que les invités restaient bien assis sur leur chaise à regarder les autres fuir devant le masque. De jeunes hommes entrèrent sur la scène installée devant les chaises et dansèrent accompagnés de leur kankurang. Le masque rendit hommage à l'organisateur du festival en s'inclinant devant lui. Puis les jeunes gardiens firent la démonstration de leur invulnérabilité magique en tailladant leurs hanches à l'aide de machettes, sans saigner. Plusieurs moments de la cérémonie initiatique furent ainsi montrés au public dans le cadre d'un festival organisé pour promouvoir la reconnaissance du kankurang en tant que patrimoine culturel immatériel. Dans ce contexte, on ne retrouvait plus le suspense et le secret qui entourent habituellement la cérémonie lors d'une initiation. Le festival, qui transforma la cérémonie en un spectacle public, introduisit également de nouveaux rapports entre les spectateurs et le spectacle. Tandis que les badauds
2. Le festival était organisé par un homme originaire de Sédhiou (connu sous le nom d'«homme de culture»), qui avait invité plusieurs troupes de danseurs à se produire. Il fut annoncé dans les médias nationaux et locaux, et trois journalistes débutants français firent le voyage depuis Dakar pour couvrir l'événement. Le festival attira de très nombreux visiteurs.

Étant donné que le spectacle eut lieu un an avant la proclamation du kankurang comme chef-d'œuvre du patrimoine oral et immatériel, je suppose que la programmation était destinée à soutenir cette candidature.

3. Touré Kunda et I'UCAS de Sédhiou, deux groupes très populaires originaires de la région, ont intégré ces chants et ces rythmes dans leurs albums, qui ont rencontré un grand succès international. Touré Kunda, en particulier, fut une figure majeure de la scène des musiques du monde dans les années 1980 et 1990. Des chants initiatiques que je croyais être toujours secrets lors de ma recherche à Ziguinchor avaient en fait déjà pénétré le marché mondial des musiques du monde.

4. Il s'agissait du principal du lycée Djignabo de Ziguinchor, Nouha Cissé. 
étaient poursuivis au hasard par le kankurang, les spectateurs assis, les participants à la conférence, purent quant à eux assister à la cérémonie sans y prendre part et sans être dérangés par le masque. Le festival établissait ainsi une différence au sein même du public: la foule poursuivie par le masque d'un côté et de l'autre les invités de marque, bien placés pour regarder la cérémonie et le public.

Les responsables politiques et les ethno-preneurs de Sédhiou étaient manifestement en quête d'une forme de patrimonialisation du kankurang très différente de celle que les notables de Ziguinchor avaient en tête. Ces derniers avaient voulu exclure jeunes et femmes afin de restaurer le secret du rite. Pendant le festival, au contraire, les jeunes comme les femmes furent invités à célébrer le patrimoine représenté par le kankurang. Et la mise en scène de la cérémonie comme patrimoine produisit de nouvelles lignes de partage au sein du public, certains devenant spectateurs des autres (voir Barber 1997; Mark 1994). Si les chants initiatiques repris en chœur pendant la cérémonie d'ouverture créèrent une certaine convivialité entre les responsables politiques et la population, la cérémonie de clôture remit chacun à sa place puisque les politiques, séparés du reste du public, regardèrent la population participer à la mise en scène de son «patrimoine». Devenu patrimoine, le kankurang produisit de nouvelles hiérarchies, les dirigeants politiques prenant la place des anciens.

\section{L'inscription à l'Unesco d'un patrimoine panafricain}

En novembre 2005, le kankurang et le rite d'initiation mandingue furent proclamés chefs-d'œuvre du patrimoine oral et immatériel de l'humanité par l'Unesco. La proposition avait été soumise conjointement par le Sénégal et la Gambie; ce fut l'un des premiers cas de candidature plurinationale. Pendant le Festival du diambadong, le maire de Sédhiou avait pourtant évoqué le kankurang en parlant d'un «patrimoine national dans une nation unie». Cette définition peut sembler contradictoire avec la proclamation par l'Unesco. En effet, dans le langage métaculturel de la production patrimoniale, la propriété culturelle du kankurang fait débat. Je vais maintenant examiner quelques aspects de l'interprétation métaculturelle de l'inscription du kankurang au patrimoine mondial.

Le dossier d'inscription de l'Unesco présente le kankurang comme le patrimoine culturel du Kaabu (ou Gabou), le royaume le plus occidental de l'empire du Mali au Moyen Âge. Aux xvı et xvII siècles, le Kaabu contribua à étendre l'influence de la civilisation mandingue à l'ouest du territoire. Le document attribue à cette expansion la diffusion des rites et leur présence actuelle en Guinée-Conakry, en Guinée-Bissau, au Sénégal et en Gambie, attestant ainsi la «propriété» mandingue du kankurang. À travers cette cérémonie, présentée comme le pilier du patrimoine culturel mandingue, c'est donc l'héritage le plus important d'une «brillante civilisation» qui est célébré. Le dossier d'inscription, qui cite les récits de voyage des premiers explorateurs portugais sur le continent africain, utilise ainsi les bibliothèques européennes pour prouver l'ancienneté des deux coutumes, que les traditions orales transmettent «depuis la nuit des temps». Or, il attribue une origine très ancienne au kankurang et au rite d'initiation dans la civilisation mandingue, les rattache à une généalogie prestigieuse en retraçant leur 
diffusion au cours de l'expansion de l'empire du Mali, rappelle quel fut leur rôle de transmission à travers ces échanges interculturels et transforme par conséquent l'héritage mandingue en un patrimoine panafricain.

Le texte de l'Unesco décrit le kankurang en termes fonctionnalistes: c'est un rituel à travers lequel s'exprime l'autorité morale des anciens - dont nous venons de voir qu'elle n'est plus reconnue par les jeunes. II remplit une fonction sociale importante en imposant aux initiés la discipline du rite d'initiation, assurant par là le maintien de l'ordre social. Même si le document évoque le contexte actuel dans lequel se déroule la cérémonie, l'analyse insiste avant tout sur la fonction du rite - restaurer l'ordre - plutôt que sur sa capacité à inspirer la révolte, comme c'est souvent le cas (De Jong 2007). La description officielle proposée sur le site de l'Unesco fait écho à cette lecture conservatrice:

Le kankurang est à la fois le garant de l'ordre et de la justice, et l'exorciste des mauvais esprits. En tant que tel, il assure la transmission et l'enseignement d'un ensemble complexe de savoir-faire et de pratiques qui constituent le fondement de l'identité culturelle mandingue ${ }^{5}$.

II est facile de voir en quoi cette interprétation recycle une vision nostalgique de la civilisation africaine. Le texte, qui présente le rite comme le dépositaire des valeurs mandingues, ne mentionne en réalité que celles soutenues par I'Unesco: le respect, la solidarité, etc. II laisse de côté celles qui ne feraient pas l'unanimité auprès d'un jury international. Nulle part ne sont mentionnés les aspects de la cérémonie - par exemple la violence du masque - incompatibles avec les droits de l'homme, dont les États modernes sont supposés être les garants. Le kankurang est ainsi un «exorciste des mauvais esprits», mais rien n'est dit sur la façon dont il s'en prend violemment aux sorcières. Afin de sauver le rituel, ses aspects les plus sombres sont passés sous silence ${ }^{6}$.

Conformément aux principes du paradigme du «sauvetage» de I'Unesco, le dossier d'inscription s'intéresse avant tout à la «banalisation » du rite. D'après le document, c'est là la conséquence de la composition multiethnique de la population des villes où est pratiqué le kankurang: les membres des groupes ethniques peu familiers du rituel ont du mal à le respecter. On estime ainsi que l'urbanisation menace l'avenir de la cérémonie. À la différence des anciens, qui font porter la faute sur une jeunesse indisciplinée, le texte de l'Unesco identifie comme causes principales de la banalisation du kankurang l'urbanisation et la modernisation. L'ironie veut pourtant que, si la modernité est certes perçue comme un facteur de banalisation de la cérémonie, celle-ci est présentée comme un rempart potentiel aux ravages de cette même modernité. La restauration du rite, qui préserve les valeurs mandingues, est ainsi nécessaire pour contrecarrer les effets néfastes de cette dernière. Le dossier poursuit en expliquant que les initiatives populaires évoquées plus haut doivent dès lors être soutenues et coordonnées par des professionnels du patrimoine. La conservation du kankurang implique une certaine officialisation, voire une bureaucratisation du rite, ce qui confirme l'idée selon laquelle l'Unesco encouragerait le développement d'une métaculture (Kirshenblatt-Gimblett 2006). L'un des objectifs est par
5. Ces valeurs sont censées être transmises dans le cadre de l'initiation, au cours de laquelle les vieilles générations enseignent aux initiés les mythes, la loi, les chants, les danses et les connaissances locales (relatives à la chasse, à l'agriculture, au climat, à la météorologie et à la médecine). Voir Le Kankurang, rite d'initiation mandingue, sur le site de la liste représentative du patrimoine culturel immatériel de l'humanité de l'Unesco: http://www.unesco.org/ culture/ich/fr/listes (2008).

6. Dans son article sur l'histoire de la politique de I'Unesco, Wiktor Stoczkowski (2009: 11) explique que le problème provient de l'incompatibilité entre les droits de l'homme et les droits culturels. 
exemple de permettre la transmission - formelle - des connaissances sur le kankurang à travers des programmes muséaux et la publication de chants initiatiques. Le texte suggère également l'utilisation de toute une série de médias pour promouvoir ce patrimoine culturel: édition de cartes postales et de vidéos, production de pièces de théâtre et d'un festival annuel, création d'un site Internet, etc. Le programme inclut même la réalisation de figurines miniatures, alors que le dossier insiste précisément sur la dimension sacrée du rituel et cherche à freiner sa banalisation...

En résumé, dans le dossier d'inscription, le kankurang et le rite d'initiation représentent le patrimoine précolonial de la civilisation mandingue. Ce patrimoine panafricain, dont on juge qu'il a survécu à la modernisation du Sénégal, fait figure de pharmakon potentiel pour panser les plaies de la modernité. Cette opération s'appuie sur la restauration de certaines valeurs associées à l'image d'un passé précolonial glorieux. En identifiant la modernité à une expérience de la perte que la restauration peut réparer, le texte reprend le paradigme du sauvetage des premiers anthropologues. Cette conception patrimoniale et, pour l'essentiel, nostalgique du rituel refuse d'accorder une quelconque validité aux conditions actuelles dans lesquelles il est pratiqué. Pourtant, les stratégies visant à préserver la cérémonie reviennent à décupler sa visibilité et peuvent ainsi contribuer potentiellement à la banalisation qu'elles sont censées combattre. Le texte de l'Unesco livre une interprétation des menaces pesant sur le kankurang très semblable à celle des anciens de la communauté mandingue, mais les mesures proposées pour remédier à ces problèmes et préserver la cérémonie sont très différentes. Tandis que les dignitaires mandingues souhaitent limiter la fréquence des cérémonies, le programme de l'Unesco cherche au contraire à diffuser les connaissances sur le masque et augmenter sa visibilité.

\section{La culture comme source et ressource}

La production culturelle du Sénégal indépendant est une mise en application de la philosophie de la négritude de Senghor. Dans cette vision utopique, le développement culturel doit ouvrir la civilisation africaine au monde (et à la francophonie en particulier) tout en la maintenant profondément attachée à l'esprit africain. Grâce au dialogue culturel, dont rend bien compte l'expression «ouverture et enracinement », la culture africaine pourrait ainsi apporter sa contribution au développement de la «civilisation de l'Universel». La philosophie de Senghor, qui se fixait pour objectif d'éviter l'aliénation culturelle - la colonisation ayant laissé dans les mémoires la peur du déracinement -, est souvent associée à un « retour aux sources ». Aujourd'hui, cette devise est très souvent reprise dans les «semaines culturelles» ou «journées culturelles» organisées dans les villages sénégalais. En Casamance, ces festivals incluent par définition des cérémonies de masques (De Jong 1999).

La spectacularisation du kankurang, qui ne dérive pas seulement de son inscription sur la liste de I'Unesco, est en réalité le résultat d'un long processus. La visibilité grandissante du rite, aujourd'hui sans précédent, est un trait distinctif de la marchandisation des traditions culturelles depuis l'époque de la colonisation et des expositions universelles. Le processus de patrimonialisation par le biais de l'Unesco en ce début du XxI ${ }^{\circledR}$ siècle n'a 


\section{SEDHIOU CARNAVAL DE "DIAMBADONG" Pour la paix en Casamance}

Par son aspect fédérateur, la culture peut être, entre autres, l'un des meilleurs facteurs de paix et de développement. Placé dans le contexte de la Casamance, le diambadong est tout trouvé. C'est un aspect culturel dans lequel s'identifient aussi bien le Sénégal que la Guinée, la Gambie, la Guinée-Bissau... Une occasion aussi de redo. rer le blason du kankourang.

\section{Boubacar CAMARA}

(Correspondant à Vélingara)

La deuxième édition du carnaval de diambadong se déroulera les samedi 4 et dimanche 5 décembre prochain à Sédhiou (région de Kolda). Elle sera placée sous le signe de la sensibilisation et la consolidation de la paix en Casamance.

Selon Kéba Dabo, promoteur de la manifestation et président du comité d'organisation, le choix d'un tel thème n'est pas fortuit. Il s'inscrit en droite ligne avec le souhait exprimé par le chef de l'Etat de voir les cadres casamançais jouer leur partition dans le processus de paix déjà enclenché.

Le diambadong, qui est une manifestation cultu slle, est $r$. artagé var là

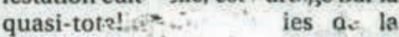
Casaman ent" , sp: ce de l'ancien ex $e_{2}$ Gi Ginée. Bissau, Gambie, Sénégai en Casamance) et même la républirue de Guinée). C'est une danse prof re à la culture mandingue qui se fait avecles feuilles d'arbre pour exprimer une joie ou fêter une victoire. L'esprit d'une telle manifestation, uc'est de créer cette cohésion sociale, une fraternisation, un grand rassemblement pour qu'on puisse renouer aved la Casamance d'antan, au clair de lune, sous l'arbre à palabresw, a précisé M. Dabo. lors du point de presse qu'il a tenu a Vélingara, quand il y est venu pour une tournée de sensibilisation. $\mathrm{Ce}$, dans l'espoir de gagner le pari de la mobilisation sociale.

Placée sous l'égide du ministère de la culture, cette deuxième édition sera parrainée par Abdoulaye Baldé, secrétaire général de la présidence de la République. Tous les maires de la Casamance y prendront part. wLa ville de Sédhiou sera trop étroite ce jour-la, pour accuellitir toute la Casamance, les ressortissants des deux pays frontaliers avec le Sénégal (la Guinée-Bissau et la Gambie) qui sont directement concernés par le conflit casamançiss, a promis M. Dabo. Lun des moments forts du carnaval sera, sans conteste, la table ronde sur le thème : $\alpha$ La culture, 'acteur de rapprochement, d'intégration et de cohésion sociale: L'exemple à diambadong", qui sera animé par Nouha Cissé, proviseur du lycée Dijgnabo de Ziguinchor. Le diambadong ne peut se faire sans le kankou. rang. Or, ce kankourang est en train d'être dévalorisé par les jeunes et les femmes dans les centres urbains. La prochaine manifestation sera donc une occasion de prouver aux nombreux participants que le vrai kankourang existe, et qu'il est esprit et unique en son genre, a conclu Kéba Dabo, Pinitiateur de ce carnaval.

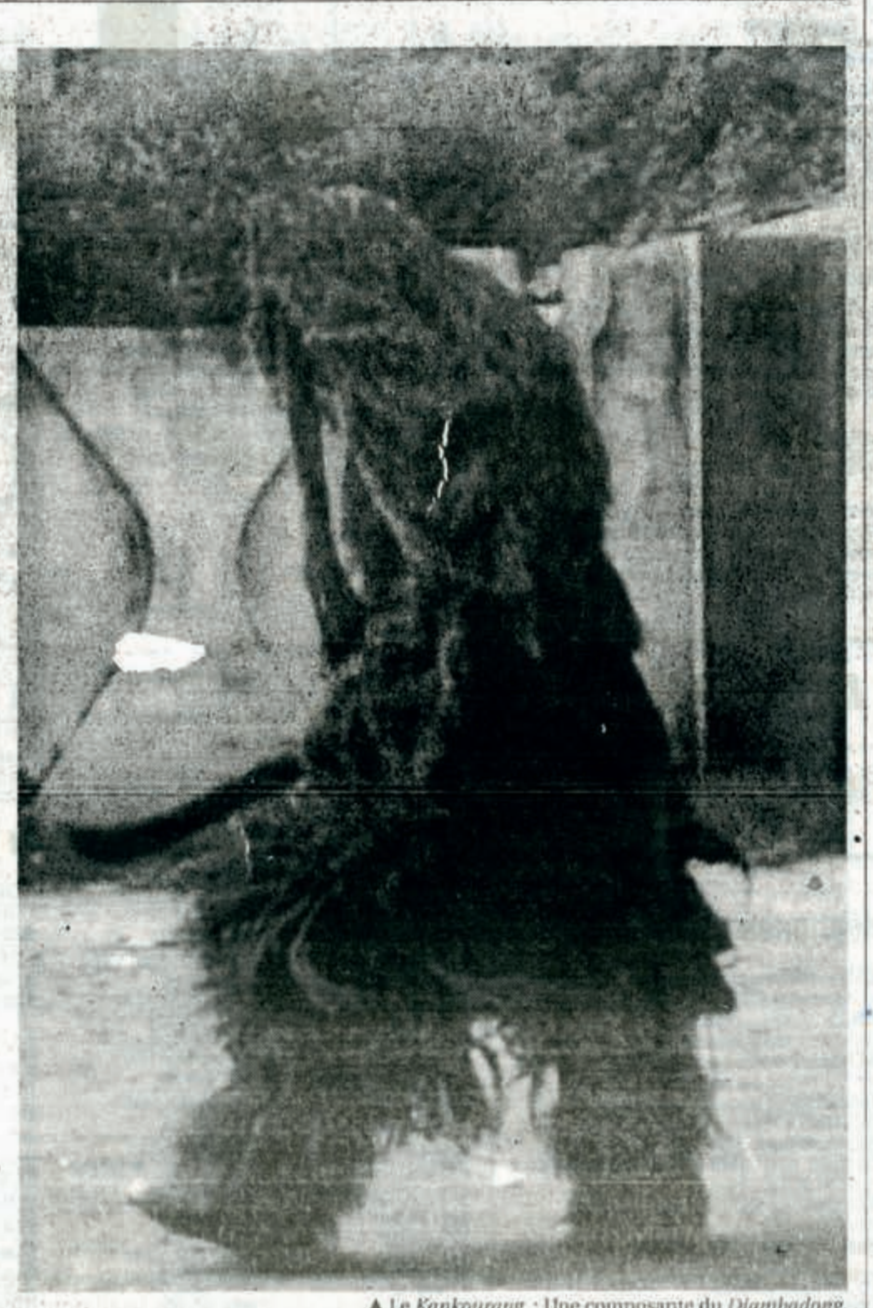

A Le Kankoumang : Unecomposante du Dlambadong.

fig. 7

Article sur le Kankurang paru

dans le quotidien sénégalais

Le Journal, 12 novembre

2004, DR. 


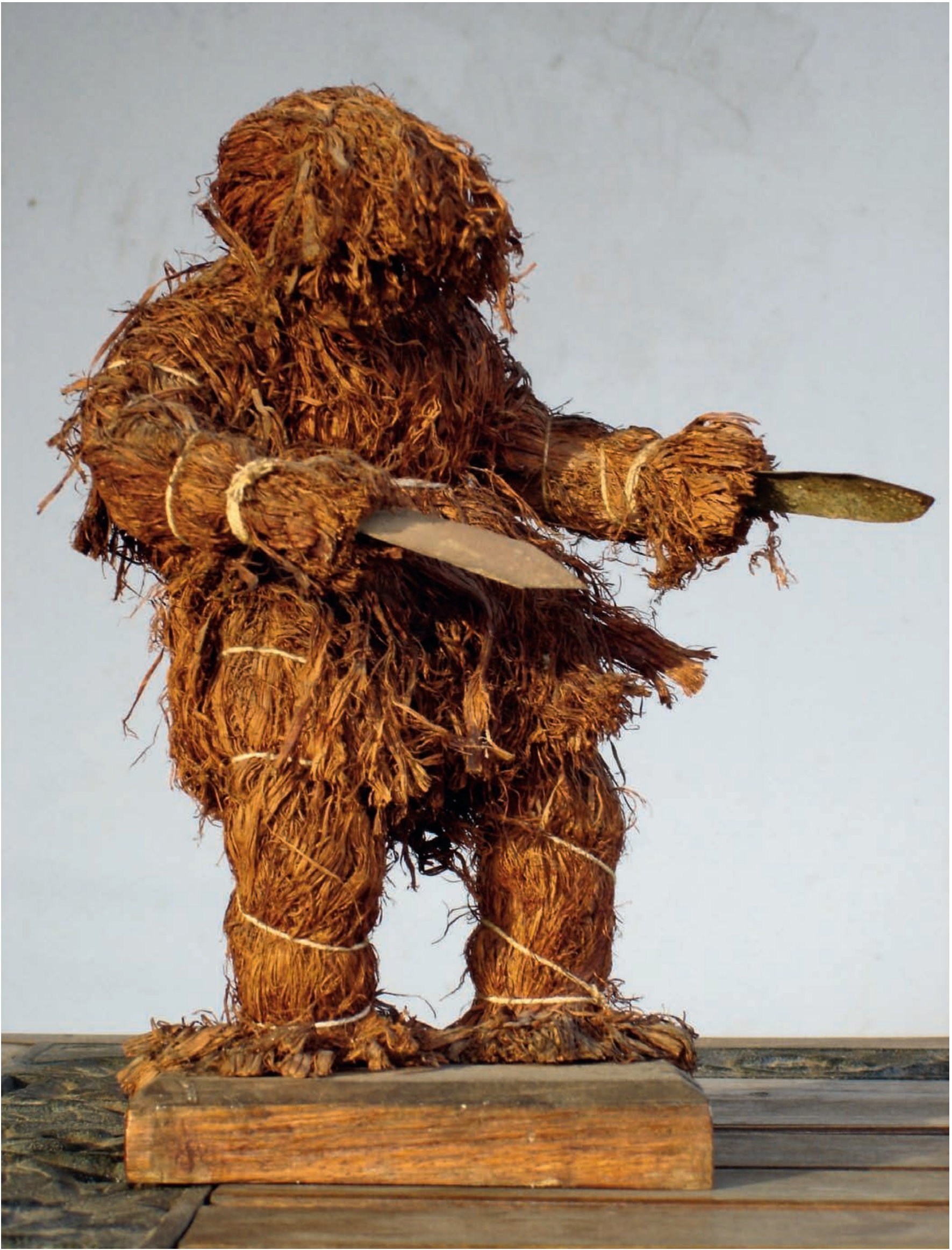


bien entendu rien à voir avec les représentations à caractère exotique qui se déroulaient dans le contexte impérialiste $d u X X^{e}$ siècle. Mais il nous faut pourtant faire référence à cette période de l'histoire pour expliquer l'historicité des phénomènes actuels et montrer que les paradoxes de cette patrimonialisation trouvent leur origine dans une production culturelle coloniale. Les empires européens exposaient aux yeux du monde entier les fruits de leur «mission civilisatrice» lors d'expositions où les «indigènes» étaient invités à faire la démonstration de leurs arts et industries. Même si la production culturelle de ces derniers était ainsi transformée en spectacle, l'accent était avant tout mis sur le message éducatif adressé aux citoyens de la métropole. La popularité croissante de l'anthropologie doit beaucoup à sa participation à la mise en scène des «primitifs » lors de ces expositions (Coombes 1994). À cheval entre l'éducation et le divertissement, celles-ci mettaient en scène des danses africaines afin de diffuser les connaissances anthropologiques. Les représentations de cérémonies africaines, l'anthropologie et le système des expositions coloniales n'empruntèrent pas des voies totalement distinctes après l'indépendance, mais restèrent au contraire intimement liés, en particulier dans le Sénégal de Senghor ${ }^{7}$.

L'histoire de l'«extraversion» du kankurang en spectacle destiné à des publics étrangers est certainement plus longue que la littérature sur la métamorphose de la culture en patrimoine ne veut bien le reconnaître. Depuis son indépendance politique, la Gambie a cherché à transformer le kankurang en patrimoine. Au Musée national de Banjul, où sont exposés une miniature et des dessins représentants différents types de kankurang, les traditions mandingues sont présentées comme faisant partie du patrimoine culturel national. Le kankurang, dont un masque est exposé au Musée national, est ainsi devenu un des symboles du pays et est utilisé par l'État gambien pour créer une culture nationale reposant pour l'essentiel sur des traditions culturelles mandingues. La Gambie a intégré la tradition dans son patrimoine afin de renforcer son projet nationaliste (voir Ebron 2002). Cette «nationalisation» de la cérémonie a semble-t-il ouvert la voie à sa marchandisation. La Gambie est une destination populaire auprès des Noirs américains qui se rendent en pèlerinage dans leur pays d'origine. Au cours du festival international Roots, qui a lieu tous les ans, des kankurang sont souvent organisés pour ces visiteurs, où ils sont présentés comme un patrimoine panafricain. Les touristes n'ont pas toujours la même interprétation de la cérémonie que les locaux. Un de ces Américains, qui avait assisté à une cérémonie au cours de son voyage en Gambie, m'envoya un jour un e-mail me félicitant pour mon important travail de recherche sur les «arts martiaux » africains...

Le fait que le kankurang est désormais conçu comme un patrimoine risque bien de contribuer à sa marchandisation croissante auprès des publics étrangers ${ }^{8}$. Quand la cérémonie est organisée pour ces spectateurs-là, il est impossible de s'assurer de leur soumission au masque. Lors de la troisième conférence de l'Association internationale des études mandingues, qui se tint en Gambie en 1998, les participants furent invités à se rendre un soir dans une salle où étaient montrées des traditions culturelles locales. Après un spectacle de «danses diola », au cours duquel certains chercheurs ne se firent pas prier pour montrer les compétences acquises sur le terrain,
7. Dans son étude du Festival des arts et de la culture négro-africains (Festac) de 1977, Andrew Apter (2005) montre que le format des festivals postcoloniaux trouve son origine dans les expositions coloniales.

8. En Gambie, la cérémonie est également transformée en «bien de consommation " pour les spectateurs locaux (voir Weil et Saho 2005).

\footnotetext{
ci-contre

fig. 8

Statuette de Kankurang

semblable à celles que

l'on trouve parfois

en vente à Ziguinchor, 2004

(C) Ferdinand de Jong.
} 
9. Pour des analyses comparables sur le patrimoine et la crise de la visibilité dans un autre contexte africain, voir Probst 2011. vint le kankurang. Inutile de préciser que le masque ne poursuivit personne: il ne fallait pas risquer de choquer les participants ignorant le déroulement du rite dans le contexte des initiations. Les spectateurs ne furent pas obligés de s'enfuir pour se cacher; on les autorisa au contraire à regarder le kankurang, à prendre des photographies et à filmer. Le mode initiatique, qui ne permet pas d'observer le masque, n'est plus le seul cadre dans lequel la cérémonie se pratique; il a laissé la place à un mode de visibilité qui nécessite la saisie instantanée du rite ${ }^{9}$.

Ce passage à la visibilité apparaît également dans la presse. Pendant les vacances d'été, en particulier, les journaux sénégalais consacrent plusieurs rubriques «éducation » à toute une série de questions sur l'histoire et le patrimoine du pays. L'article évoque généralement une tradition, selon une conception nostalgique tout à fait similaire à celle du patrimoine panafricain. À chaque fois, le texte fait référence aux aspects magiques de ces traditions, sans toutefois s'y attarder; mais c'est toujours là une manière implicite de les authentifier comme tradition africaine. Nombreux sont les articles sur le kankurang qui le présentent comme une tradition sénégalaise, les illustrations étant souvent des photographies du masque (fig. 7). De plus en plus, celui-ci est donc représenté à travers une technique de reproduction mécanisée, la photographie, qui transforme la cérémonie en objet à regarder. La photographie n'est pas la seule à proposer cette image. Plusieurs tableaux du peintre sénégalais Omar Camara représentent le kankurang. Dans l'un d'eux, le masque enlève le tissu d'écorce qui lui recouvre la tête à l'aide d'une de ses machettes. Au lieu de dévoiler le visage du personnage, la peinture montre une zone sombre et mystérieuse. En jouant ainsi avec le secret et la révélation, le tableau ne les viole pas mais contribue au contraire à les renforcer. Le masque devient néanmoins un objet de contemplation: même la représentation la plus mystérieuse ne peut faire aussi peur que la cérémonie elle-même. Le kankurang, qui ne doit pas être vu par les non-initiés, se mue en objet de contemplation à distance.

Ce ne sont pas là les seules façons dont le kankurang est «objectifié». Les magasins pour touristes de Ziguinchor vendent des figurines le représentant (fig. 8). Sur les trottoirs, des mannequins grandeur nature du kankurang, figés dans telle ou telle posture, font la publicité de cet art touristique. S'il est facile de voir là une autre dimension de la banalisation de la cérémonie, cela fait également partie des mesures de conservation proposées dans le dossier de candidature de l'Unesco. La production de cérémonies et de figurines pour les touristes participe du processus d'objectification par lequel les spectateurs sont invités à regarder le masque. Paradoxalement, la promotion du patrimoine immatériel que représentent les valeurs culturelles mandingues repose sur leur matérialisation sous forme de marchandises. Cependant, cette extraversion de la cérémonie en biens de consommation est en même temps un moyen de chercher à faire reconnaître le kankurang comme tradition africaine ancienne (voir Comaroff et Comaroff 2009).

\section{La reproductibilité mimée}

Le fait que la cérémonie change de contexte en passant d'un rite religieux à un patrimoine implique également le passage du registre du secret 
rituel à celui de la reconnaissance internationale. Tandis que le masque s'assurait le contrôle sur les spectateurs en se lançant à la poursuite des sorcières, il est désormais lui-même soumis aux regards scrutateurs des touristes, anthropologues et professionnels du patrimoine. Mais il faut être prudent et ne pas séparer de manière trop tranchée les registres de l'initiation et de la reconnaissance. Si l'un et l'autre sont fondés sur des modèles différents de représentation culturelle - dimension secrète contre dimension publique -, ils ont tous deux participé à l'extraversion des spectacles culturels à destination du public étranger depuis la période coloniale.

En 1939, un prêtre catholique publia la description d'un camp d'initiation de Ziguinchor et d'une cérémonie kankurang (Doutremépuich 1939). L'auteur décrivit celle-ci comme une pratique superstitieuse, mais il remarqua également que le rite se déroulait devant des touristes français. Dans l'entre-deux-guerres déjà, le kankurang avait donc été transformé en spectacle pour touristes par des locaux désireux d'empocher quelques sous. Après l'indépendance, il fut également pratiqué dans d'autres contextes que celui des initiations. L'un des organisateurs les plus vénérés des cérémonies initiatiques de Ziguinchor fut à l'origine de ces spectacles. Salif Touré, un forgeron, organisa dans les années 1970 et 1980 plusieurs initiations dans la brousse qui entoure Ziguinchor. En vertu de leurs pouvoirs surnaturels, les forgerons sont désignés pour pratiquer les circoncisions, comme ce fut le cas pour Touré. Mais le même homme - détenteur des secrets de l'initiation - organisa aussi plusieurs kankurang lors de festivals culturels dans différents stades de Dakar. Certains habitants de Ziguinchor lui reprochèrent de ne pas respecter suffisamment le secret de la cérémonie. Cet exemple montre clairement comment les spécialistes du rituel euxmêmes ignorent volontiers la frontière entre rite et spectacle. Au Sénégal, il n'est pas évident de faire la distinction entre la culture comme source et comme ressource. Les registres de l'initiation et de la reconnaissance reposent sur des valeurs distinctes, mais il n'est pas toujours possible de déterminer en quoi celles-ci sont contradictoires. En réalité, révélation et reconnaissance vont souvent de pair ${ }^{10}$.

Dans un retournement inattendu, les acteurs de la cérémonie euxmêmes ont proposé une lecture réflexive du processus de reconnaissance. Pour illustrer ce point, je vais commencer par une petite scène très révélatrice. En 2004, je vivais dans un quartier de Ziguinchor où les initiés étaient baignés dans une rivière avant d'être reconduits chez eux au rythme d'une danse festive du diambadong. Tous les samedis du mois de septembre, des dizaines de kankurang traversaient le quartier pour accompagner les initiés. Un jour où je les regardais passer, mon appareil photo à la main, l'un des gardiens du masque me dit: «\|l est formellement interdit de photographier le kankurang! » On aurait dit là les propos d'un bureaucrate sénégalais, mais ce n'était en fait qu'une des multiples façons d'inclure d'autres discours dans la cérémonie. Un autre gardien du masque s'écria: «C'est notre tradition! C'est tout ce qui reste de notre tradition! " L'idée selon laquelle les traditions disparaissent sous les coups de buttoir de la modernité évoque évidemment le paradigme du sauvetage à l'origine de l'inscription du kankurang sur la liste de I'Unesco. La scène que je viens de décrire laisse penser que cette nostalgie fait partie intégrante de la cérémonie. En définitive, les pratiquants,
10. Fred R. Myers (2004) traite de différents cas de conflits entre ces registres dans son excellent article sur les risques de la marchandisation de l'art aborigène dans le contexte d'une remise en question de la propriété indigène et des droits d'auteurs (inter)nationaux. Pour une analyse des interprétations contradictoires de la culture comme patrimoine et propriété, voir le numéro spécial d'Ethnologia Europaea (2009). 


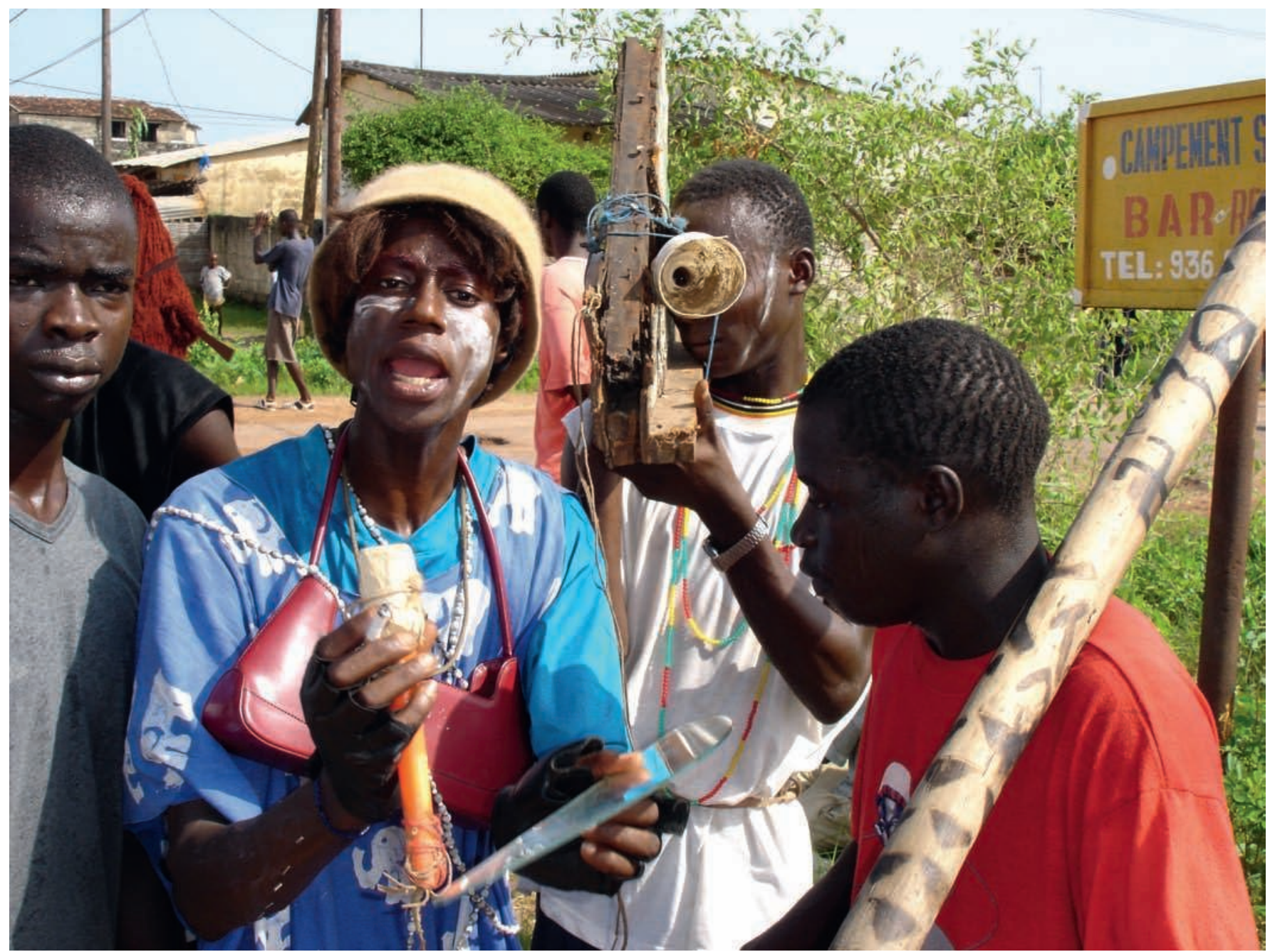

fig. 9

Acteurs armés de fausses caméras mimant les journalistes, 2004. (C) Ferdinand de Jong. en tant que sujets sénégalais, ont bien conscience que la cérémonie figure sur la liste de l'Unesco, et ils peuvent ainsi intégrer le discours nostalgique dans leur performance.

Cependant, il existe une différence importante entre les jeunes pratiquants du kankurang et les bureaucrates investis dans la patrimonialisation de la cérémonie: ces derniers se fondent sur un scénario rituel qui trouve son origine dans un modèle dépassé et gérontocratique, tandis que la jeunesse de Ziguinchor participe au rite sur un mode ludique et improvisé. Les jeunes ne cherchent pas à rendre le kankurang compatible avec les standards requis pour la reconnaissance nationale et internationale de la cérémonie, et ils s'amusent beaucoup à transformer ce rite impressionnant en une mimique de la modernité. En 2004, je remarquai que certains pratiquants avaient fabriqué de faux appareils photo à l'aide de bouteilles en plastique et de matériaux récupérés, et qu'eux-mêmes étaient travestis (fig. 9). Ils faisaient semblant de photographier la cérémonie. Ils étaient très fiers de leur petit spectacle et m'autorisèrent à les photographier contre paiement. L'ironie de la situation ne m'échappa pas: je dus payer pour obtenir une photographie où j'étais moi-même mimé. Après avoir reçu leur 
rémunération, ils repartirent rapidement au rythme du diambadong. Ils n'autorisaient aucune question. En mimant les photographes, ces danseurs reconnaissaient l'intérêt porté aux reproductions mécanisées du masque et, dans le même temps, attiraient l'attention sur leurs propres qualités photogéniques en tant qu'acteurs de la cérémonie. Mais si, à travers le processus de mimêsis, la copie possède également le pouvoir de l'original (Taussig 1993), alors, par leurs imitations, ces jeunes hommes s'approprient la reconnaissance qui s'effectue par le regard du spectateur. En effet, ils m'autorisèrent à prendre une photographie mais pas à poser des questions: c'étaient bien eux qui tenaient le micro et l'appareil (voir fig. 9). Grâce aux faux appareils qu'ils avaient fabriqués, ils endossaient le pouvoir de l'original (l'appareil photographique) et s'appropriaient la reconnaissance accordée à leur performance.

\section{Registres de la reconnaissance}

J'ai montré qu'il fallait replacer l'inscription du kankurang sur la liste du patrimoine immatériel de l'Unesco à la fois dans les débats locaux et dans les transformations qui, à l'échelle internationale, affectent les traditions rituelles. Dans le cadre des rites initiatiques, les cérémonies font l'objet de négociations entre les différentes classes d'âge qui se disputent la propriété du secret dont la révélation revient à profaner la cérémonie. Mais, de plus en plus, celle-ci est mise en scène afin d'obtenir la reconnaissance internationale et profiter des retombées financières que procurent ces spectacles à destination des étrangers. Elle se déroule alors dans un cadre préétabli, celui qui sert pour toutes les représentations du patrimoine africain. Dans les festivals postcoloniaux, lieux d'une certaine affirmation panafricaine, le format adopté pour la représentation de traditions africaines très respectées est en grande partie hérité de ceux fixés lors des expositions coloniales organisées par l'empire français. Les productions culturelles du tiers monde sont ainsi apparues dans une économie du signe où tradition signifie «racines " et «authenticité 11 ». Après l'indépendance, la vision utopique de Senghor se fondit dans la nostalgie impérialiste de l'anthropologie française et fit appel à la tradition pour montrer la contribution de l'Afrique à la civilisation de l'Universel naissante. Aujourd'hui encore, la reconnaissance de la production culturelle africaine se fonde sur cette nostalgie impérialiste. II faudrait dès lors replacer celle du kankurang en tant que patrimoine culturel immatériel dans une politique de la reconnaissance culturelle dont les racines remonteraient à la production culturelle impérialiste. Cependant, dans le contexte postcolonial, les cérémonies mises en scène pour obtenir la considération de la communauté internationale restent soumises à une politique d'authentification élaborée localement. Comme nous l'avons vu dans l'anecdote relatée plus haut, les pratiquants intègrent des éléments métaculturels dans leur cérémonie, qui prend dès lors un tour réflexif. La distinction précise entre une culture ethnique soi-disant authentique d'un côté et, de l'autre, une production métaculturelle réflexive ne peut être maintenue dans le cas de traditions qui, pendant plus d'un siècle, n'ont cessé d'être à cheval entre ces catégories.
11. Comme David Murphy

(2012: 25) l'a souligné,

on commence à peine

à prendre conscience de

l'hybridité culturelle qui

résulte de ce processus.

\section{remerciements}

Cet article est le fruit d'un long travail de recherche en Casamance débuté en 1990. Je remercie Mohamed Mané pour sa collaboration. Un grand nombre d'institutions ont financé mon travail de terrain, la plus récente étant l'Economic and Social Research Council (référence de la bourse: RES-000-22-0735). Pour la rédaction de cet article, j'ai bénéficié d'une bourse de la British Academy (référence MD120035). Ma gratitude va également aux deux évaluateurs de Gradhiva, grâce à qui j'ai pu sensiblement améliorer mon texte. 
Bibliographie

\section{Apter, Andrew}

2005 The Pan-African Nation: Oil and the Spectacle of Culture in Nigeria. Chicago-Londres, Chicago University Press.

\section{Barber, Karin}

1997 "Preliminary notes

on audiences in Africa",

Africa 67(3) : 347-362.

\section{Baudrillard, Jean}

1981 Simulacres et Simulations.

Paris, Galilée.

\section{Benjamin, Walter}

2003 L'CEuvre d'art à l'heure de sa reproductibilité technique. Paris, Allia.

\section{Boym, Svetlana}

2001 The Future of Nostalgia. New York, Basic Books.

\section{Clifford, James}

1996 Malaise dans la culture. L'ethnographie, la littérature et l'art au $x x^{e}$ siècle. Paris, École nationale supérieure des beaux-arts.

\section{Comaroff, John L.} et Comaroff, Jean 2009 Ethnicity, Inc.

Chicago-Londres, University of Chicago Press.

\section{Coombes, Annie E.}

1994 Reinventing Africa: Museums, Material Culture and Popular Imagination.

New Haven et Londres, Harvard University Press.

\section{De Jong, Ferdinand}

1999 «Trajectories of a mask performance: The case of the Senegalese Kumpo ", Cahiers d'études africaines 153: 49-71.

2007 Masquerades of Modernity: Power and Secrecy in Casamance, Senegal. Édimbourg, Edinburgh

University Press for the International African Institute.

Le secret exposé. Par Ferdinand de Jong

De Jong, Ferdinand et Rowlands, Michael (éd.)

2007 Reclaiming Heritage:

Alternative Imaginaries of Memory in West Africa. Walnut Creek, Left Coast Press.

Doutremépuich, Émile

1939 "Visite à un "camp"

de circoncis en Casamance",

Les Missions catholiques 72 :

474-477, 486-492.

\section{Ebron, Paulla}

2002 Performing Africa. Princeton, Princeton University Press.

\section{Ethnologia Europaea}

2009 Culture and Property,

numéro spécial 39(2).

\section{Kirshenblatt-Gimblett,}

\section{Barbara}

2006 «World heritage and cultural economics ", in Ivan Karp et al.

(éd.), Museum Frictions: Public

Cultures/Global Transformations.

Durham, Duke University Press: 161-202.

\section{Mark, Peter}

1994 «Art, ritual, and folklore: Dance and cultural identity among the peoples of the Casamance",

Cahiers d'études africaines 34(136): 563-584.

\section{Murphy, David}

2012 «Culture, empire and

the postcolony: From la

Françafrique to le Festival mondial des arts nègres (1966 et 2010)",

Francosphères 1(1): 19-33.

Myers, Fred R.

2004 « Ontologies of the image

and economies of exchange",

American Ethnologist 31: 5-20.

\section{Probst, Peter}

2011 Osogbo and the Art of

Heritage: Monuments, Deities,

and Money. Bloomington,

University of Indiana Press.
Rowlands, Michael

2007 «Entangled memories

and parallel heritages in Mali ",

in De Jong et Rowlands (éd.) 2007 127-144.

Smith, Laurajane et Akagawa, Natsuko (éd.)

2009 Intangible Heritage,

Londres-New York, Routledge.

\section{Spyer, Patricia}

2001 «The Cassowary will

(not) be photographed:

The "primitive", the "Japanese",

and the elusive "Sacred"

(Aru, Southeast Moluccas)",

in Hent de Vries et Samuel Weber (éd.), Religion and Media. Palo Alto, Stanford University Press : 304-319.

\section{Stoczkowski, Wiktor}

2009 "Unesco's doctrine of human diversity: A secular soteriology? ", Anthropology Today 25(3) : 7-11.

\section{Taussig, Michael}

1993 Mimesis and Alterity:

A Particular History of the Senses.

Londres, Routledge.

\section{UnescoPress}

2005 «The Samba of Roda and the Ramilia proclaimed masterpieces of the Oral and Intangible Heritage of Humanity ", communiqué de presse $n^{\circ}$ 2005-144. Paris, Unesco.

Weil, Peter et Saho, Bala 2005 "Masking for money:

The commodification of Kankurang and Simba mask performances in urban Gambia ", in Stephan Wooten (éd.), Wari Matters: Ethnographic Explorations of Money in the Mande World. Münster, Lit Verlag: 162-177.

page 98 et ci-contre Dessin de Samba Fall paru dans le quotidien sénégalais Le Soleil montrant le Kankurang en train de pourchasser un photographe. 17-18 septembre 1988, DR.

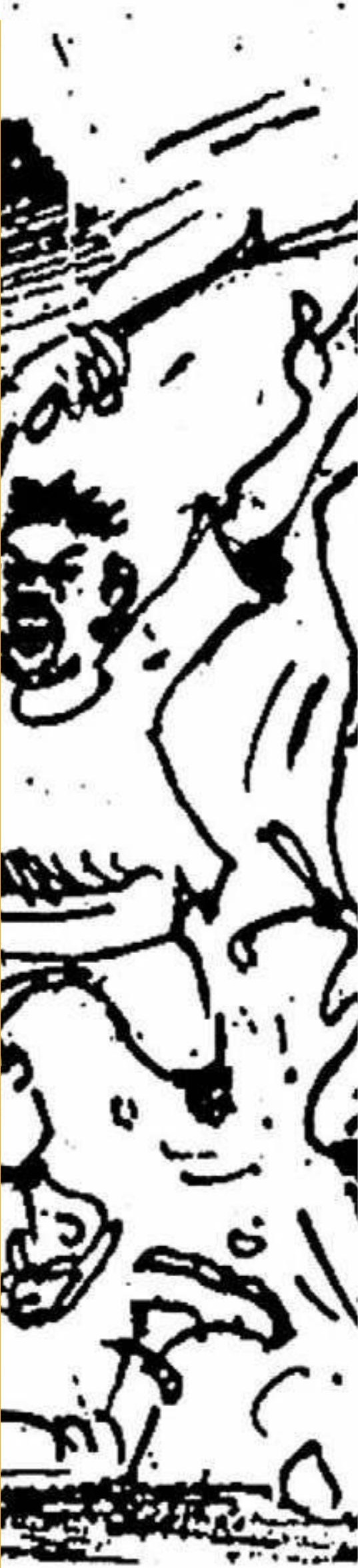




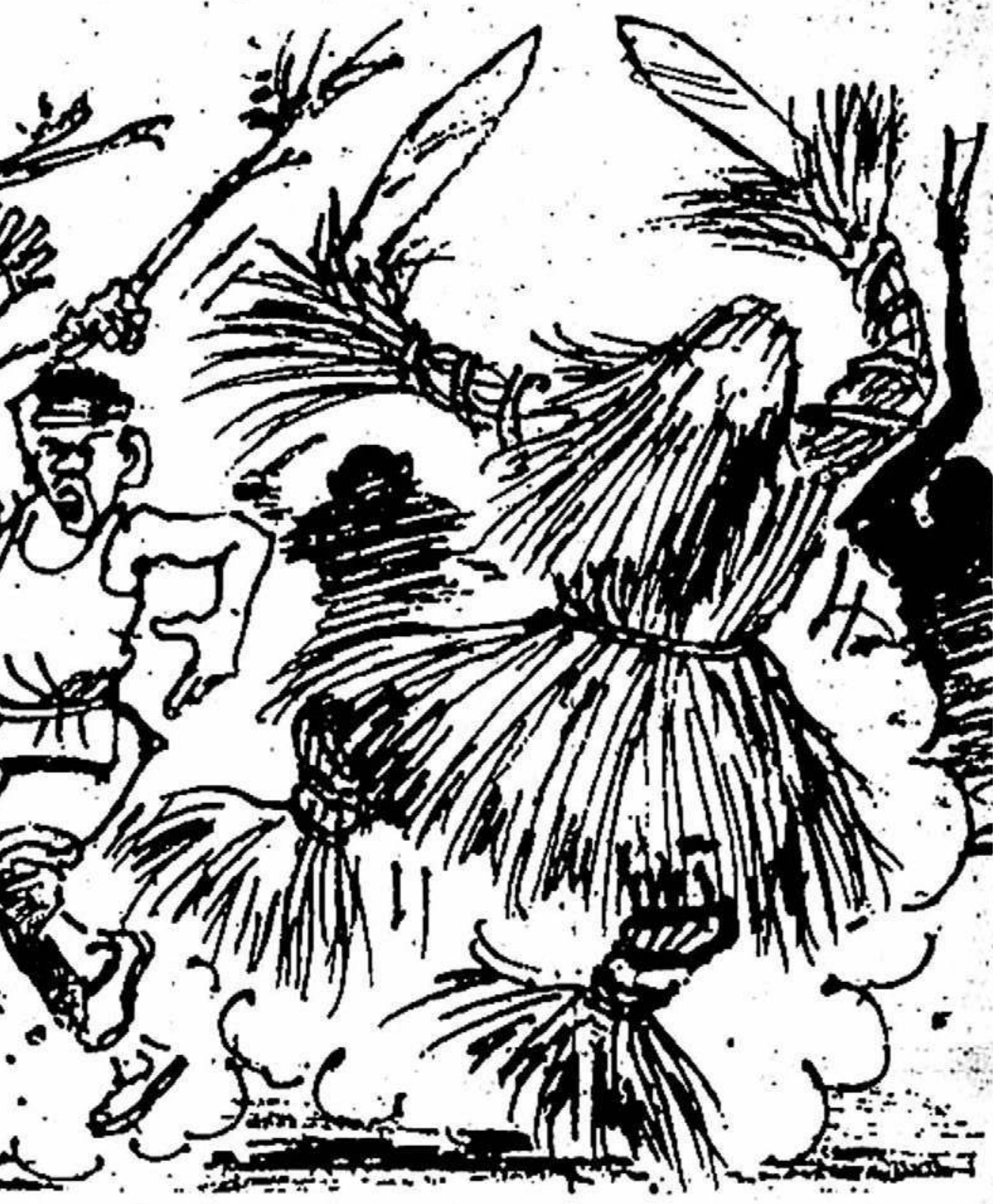

